\title{
Uma investigação do ser-aí do menino selvagem à luz do pensamento heideggeriano
}

\author{
Ana Mania Lqpez CalvodeFëjœ- UniversidadedoEstadodoRiodeJaneiro Maracanã, RiodeJaneiro, Brasil \\ Débara Gill - Pontifíaa UniversidadeCatdica doRiodeJanèro, Gávea, RiodeJanèro, Brasil \\ MyriamMorera Prdasio- UnivesidadedoEstadodbRiodeJanero, Maracanã, RiodeJanero, Brasil
}

\begin{abstract}
Resumo
Este trabalho busca, na história de Victor de Aveyron, elementos para discutir o modo pelo qual a existência humana se constitui. Por não ter convivido em ambiente humano, Victor foi motivo de intensas discussões no meio científico, especialmente entre os empiristas e os racionalistas. Nesta pesquisa assumimos uma postura fenomenológica, trazendo a história do menino selvagem à discussão por meio da fenomenologia hermenêutica de Heidegger, apontando, assim, para o caráter de indeterminação, o "ter de ser", e de singularidade da existência, sempre em jogo na constituição do modo de ser do homem.

Palavasdhave Criança; Hermenêutica; Ser-aí; Heidegger; Menino selvagem.
\end{abstract}

\section{An investigation of the Dasein of the wild boy through Heidegger's thought}

\begin{abstract}
This work aims to find, in the story of Victor of Aveyron, elements to discuss the way in which human existence is constituted. For not having lived in the human environment, Victor was the subject of intense discussions within the scientific community, especially among empiricists and rationalists. In this research we take a phenomenological approach, bringing the story of the wild boy into the discussion through the Heidegger's phenomenology hermeneutic, pointing to the character of indeterminacy, mineness; and the singularity of the existence, always presented in the constitution of man's way of being.
\end{abstract}

Kegwards Child; Hermeneutic; D asein; Heidegger; Wild boy.

Una investigación del ser-ahí del niño salvaje a luz del pensamiento heideggeriano

\begin{abstract}
Resumen
Este trabajo busca en la historia de Víctor de Aveyron elementos para discutir el modo por el cual la existencia humana se constituye. Por no haber convivido en ambiente humano, Víctor ha sido motivo de intensas discusiones en el medio científico, especialmente entre los empiristas y los racionalistas. En esta investigación asumimos una postura fenomenológica, trayendo la historia do menino salvaje a discusión por medio de la fenomenología hermenéutica de Heidegger, apuntando, así, para el carácter de indeterminación, o "tener de ser", e de singularidad de la existencia, siempre en juego en la constitución del modo de ser del hombre.

Palabrasdave Niño; Hermenéutica; Ser-ahí; Heidegger; Niño salvaje.
\end{abstract}

Ao apresentar a infância e a experiência infantil em uma hermenêutica fenomenológica e existencial, muito frequentemente surgem questões acerca da possibilidade de se pensar a criança como um existir que traz em sua constituição o caráter de indeterminação e consequente liberdade. Muitas são as dúvidas quanto às condiç̃oes de indeterminação e de liberdade em uma etapa de vida em que o homem não pode ser responsabilizado pelas suas escolhas. Ainda, com relação ao caráter de indeterminação surge 0 seguinte questionamento: como podemos explicar 0 choro do recém-nascido, o seu estado de sonolência e a sucção, se não for pela determinação biológica? Segundo Sawrey e Telford (1958/1967), é preciso afirmar as contribuições da hereditariedade para compreender as influências do meio. Sobre a natureza boa e ingênua da criança, o que dizer àqueles que adotam uma perspectiva romântica ao afirmarem que tal natureza se desvirtua pela influência da cultura? Rousseau (citado por G runsburg, 2008), defende que é a cultura que corrompe o homem, pois este, em seu estado infantil e selvagem, é integro, porque ainda não se corrompeu. E o que poderemos responder aos behavioristas quando afirmam que é 0 mundo que constitui a criança, a qual, por sua situação de folha em branco ou tábula rasa, pode ser constituída segundo única e exclusivamente os condicionamentos do mundo? Watson (1930) argumenta com relação ao modo como podemos fazer com que crianças se tornem aquilo que fizermos delas.

Os estudiosos da psicologia do desenvolvimento infantil se dividem. Há, tradicionalmente, os inativistas, que defendem a posição de que o determinante do desenvolvimento da criança é biológico. E há os ambientalistas, que tecem convincentes argumentos em defesa dos determinantes sociais ou ambientais. E, ainda, há os que assumem um posicionamento de conciliação entre esses dois fatores determinantes, como, por exemplo, Jean Piaget e sua teoria do desenvolvimento cognitivo. Para Piaget (1964/1972) dois são os elementos que se retêm ao biológico. São eles 0 estremecer frente à falta de apoio e 0 estremecer frente ao som. Esse estudioso do desenvolvimento infantil pressupõe que é a partir dessas estruturas inatas 
iniciais que todo o desenvolvimento cognitivo se dá, por meio das estimulações ambientais. Na perspectiva fenomenológico-existencial, fundamentada no pensamento de Heidegger acerca do ser-aí da criança (1928/ 2008), ousamos afirmar que nem mesmo essas duas reações são consideradas originárias, logo não são determinantes do comportamento humano. Estremecer, sugar e chorar são atos, e como tal são intencionais (Feijoo, 2011). A intencionalidade diz respeito à imanência, espaço no qual as coisas se dão. Husserl (1900/2007) tenta, pela intencionalidade, resolver as hipostasias realistas e idealistas que pressupõem a origem do comportamento, seja na exterioridade ou na interioridade. Concluímos, assim, que estremecer é ato, indicando que se trata de um comportar-se em relação a algo, e que esse comportarse ainda não tem uma finalidade determinada. Basta um leve ruído para que 0 ato de estremecer da criança apareça, denotando o seu caráter intencional. Para Heidegger (1928/2008), a "reação" da criança tem efetivamente 0 caráter de choque, bem como 0 primeiro choro, já é um choque bem determinado, portanto intencional. Ainda em Heidegger encontramos, mais detalhadamente, considerações acerca do sentido da existência nos primeiros anos de vida, considerando a intencionalidade, o aí, como 0 espaço de realização do ser-aí da criança.

A fim de esclarecermos mais detalhadamente 0 caráter intencional da constituição da existência, tal como pensado por Heidegger como presente no existir na primeira etapa de vida, recorreremos, a título de exemplificação, à história de Victor de Aveyron, jovem que viveu isolado dos homens grande parte da sua infância. Victor foi encontrado, nos idos de 1799, em Aveyron, França, em um meio selvagem onde vivera cerca de oito anos. Contava, então, com aproximadamente 12 anos de idade. Esse menino, pelo fato de não ter convivido em ambiente humano, foi motivo de longas e intensas discussões no meio científico. Os investigadores dos fatores de determinação do humano acreditavam que nesse menino encontrariam as respostas para as intermináveis discussões. Falso engodo, as discussões, além de se prolongarem, detinham-se nos indícios que comprovavam as suas teorias. Os ambientalistas diziam que 0 menino, por não ter recebido estímulos humanos, não se tornou humano, o que só aconteceria por meio dos estímulos e condicionamentos. As evidências dessas teses eram de que ele andava curvado e trotando, pois não aprendera com os homens a andar como os homens andam. Não falava, porque não tinha aprendido os fonemas, justamente, porque não havia recebido estímulos humanos. Os inativistas afirmavam que 0 caráter do humano estava presente em Victor; no entanto, seu potencial para comportar-se como humano, dentro dos referenciais de normalidade, estava comprometido, visto que se tratava de um idiota.

Em nossa visada, acerca do ser-aí da criança, defenderemos um posicionamento fenomenológico, ou seja, iniciaremos com a desconsideração de todas as hipostasias, seja ambientalista ou inativista, para então pensarmos o homem em sua co-originalidade com 0 mundo. A co-originalidade diz respeito ao fato de que nem é o mundo que posiciona 0 homem, tese ambientalista, nem é o homem que posiciona o mundo, tese inativista. Logo, Victor não se comporta como os homens se comportam, mas se comporta e se relaciona com as coisas que se encontram em seu mundo, ao modo do manuseio, como defende Heidegger em Sere tempo (1927/ 1988). Eis o caráter de co-originalidade homem/ mundo presente na existência de Victor.

Após assumirmos uma postura antinatural, tal como proposta por Husserl (1952/1910), traremos à discussão, por meio da fenomenologia hermenêutica e da perspectiva existencial, o caráter de indeterminação, de ter de ser e de singularidade da existência, sempre em jogo na constituição do modo de ser do homem. Heidegger (1928/ 2008) refere-se ao ser-aí do homem, que, em seu caráter de poder-ser, se afasta de qualquer posicionamento que pressuponha determinações aprioristicamente dadas e assume um posicionamento existencial. $\mathrm{O}$ problema anunciado pelo caso Victor de Aveyron, assim como por outros casos de "meninos selvagens" que povoam as investigações em psicologia, pode ser resumido da seguinte forma: como um humano se constitui como humano? A psicologia tem recorrido, na tentativa de responder a essa pergunta, a matrizes inativistas, ambientalistas e evolucionistas, as quais, em seus desdobramentos na psicologia, recebem as denominações de comportamentalistas, psicanalíticas, humanistas, entre outras. Este texto pretende apontar outra possibilidade de investigação do problema, seguindo a orientação fenomenológica hermenêutica de Martin Heidegger.

A análise fenomenológica hermenêutica na investigação do ser-aí da criança, a partir da história do menino Victor de Aveyron, será empreendida neste trabalho da seguinte forma: primeiramente, ao assumir uma postura fenomenológica ante 0 fenômeno do menino selvagem, queremos deixar claro que nos conduziremos ao fenômeno tal como ele se dá em sua mobilidade estrutural, ou seja, sem nenhuma mediação dos pressupostos teóricos acerca do desenvolvimento infantil, tal como proposto por Husserl em A fenomendoga com aênaia rigrosa (1952). Ao incluirmos a hermenêutica nessa forma de conduzir a investigação, acompanharemos Heidegger em Ser e tempo 
(1927/ 1988), quando afirma que em toda e qualquer interpretação há sempre uma pré-compreensão que não pode de forma alguma ser suspensa. $E$, por fim, ao tomarmos a criança como um ser-aí, teremos como referência o texto Introdução à filosofia (1928/ 2008), no qual Heidegger tematiza essa questão. Em seguida, com base nas considerações de Itard (1801/2000; 1806/2000), apresentadas no relatório entregue ao Ministro do Interior sobre os novos desenvolvimentos e o estado atual do Selvagem de Aveyron, poderemos refletir sobre o caráter intencional em que a existência se constitui.

\section{A históia domenimoVidar deAvegron}

A história de Victor, apresentada a seguir, foi retirada dos relatórios do Dr. Itard, médico e tutor que cuidava do menino juntamente com a senhora Guérin, sua governanta. Primeiramente mostraremos como Itard se posiciona, de maneira geral, de forma contrária e crítica com relação às conclusões inativistas. Depois, apontaremos para suas teses ambientalistas, que fundamentam a maioria de seus posicionamentos pelo princípio da aprendizagem. $\mathrm{Na}$ perspectiva ambientalista, empreendida no início do século XIX por Itard, estima-se que tudo é aprendido: a imitação, as sensações, os atos que consideraríamos reflexos, a vida em sociedade, a comunicação, a linguagem, a vida sexual, as faculdades mentais, dentre as quais a memória, o juízo, a moral e 0 afeto (Itard, 1806/ 2000). Tais considerações vão ao encontro das teses behavioristas de 1930, nas quais Watson exprime-se da seguinte forma:

D eem-me um bebê e o meu mundo para criá-lo e eu fá-lo-ei engatinhar e caminhar; fá-lo-ei trepar e usar as mãos para construir casas de pedra ou madeira; farei dele um ladrão, um pistoleiro ou um toxicômano. A possibilidade de moldá-lo em qualquer direção é quase infinita (Watson, 1930, p. 82).

Victor foi encontrado com cerca de 12 anos, no ano de 1799 em Aveyron, ao redor dos bosques de Caunes, na França. Foi enviado para a recém-fundada Sociedade dos O bservadores do Homem de Paris, para um diagnóstico mais concreto que seria efetuado pelo psiquiatra Phillip Pinel, médico chefe do Hospital Salpêtrière e membro da Sociedade dos O bservadores. Pinel e a sociedade consideraram o menino um idiota, motivo pelo qual acreditaram que ele havia sido abandonado na floresta pelos pais. É curioso analisar 0 olhar médico da época, em sua busca por respostas conclusivas e seguras sobre a observação do homem. Será que todos que não se encaixavam no padrão observado anteriormente poderiam ser considerados idiotas?
O menino foi alvo de observações e discussões entre os estudiosos do tema, que viram apenas uma criança imunda, afetada por movimentos espasmódicos, mordendo e arranhando os que chegavam perto e, como afirmava Itard (1801/2000), uma criança que parecia indiferente a tudo. Em seu relatório, enviado por carta ao Ministro do Interior, Itard assegura que, para ser julgado devidamente, Victor só poderia ser comparado a ele mesmo. Afirma, sobretudo, que julgamos sempre segundo a nossa situação. Segundo ele, Pinel, em seus relatórios, descreve Victor com seus sentidos reduzidos a um estado de inércia, o que o colocava em posição inferior a alguns de nossos animais domésticos. Seus olhos sem fixidez erravam vagamente de um objeto a outro, sem se deter em nenhum; não distinguia um objeto de relevo de um corpo em pintura; o órgão da audição era insensível aos mais fortes ruídos bem como à música mais tocante; o da voz, reduzido à quase completa mudez; o olfato tão pouco cultivado que não diferenciava o aroma dos perfumes das fezes em sua cama; 0 órgão do tato, restringido às funções mecânicas da apreensão dos corpos. Quanto às funções intelectuais, ainda segundo Pinel, o menino era quase totalmente incapaz de atenção e desprovido de memória, de julgamento, de comunicação e aptidão para imitação, não conseguindo nem mesmo abrir uma porta ou subir numa cadeira para alcançar os alimentos que eram levantados fora do alcance de suas mãos. Ele passava, com rapidez, e "sem nenhum motivo presumível, de uma tristeza apática às mais imoderadas gargalhadas [...] toda a sua existência, numa palavra, uma vida puramente animal" (Itard, 1801/2000, p. 132).

Posteriormente, o menino foi examinado pelo Dr. Itard, que, ao contrário dos demais, acreditava que Victor estava longe de ser um idiota e criticava a limitação metafísica dos relatores, tendo em vista os preconceitos em que sempre decaíam. Dizia Itard:

D esprovidas dessas vantagens, as outras crianças, encontradas num estado de isolamento individual, trouxeram à sociedade apenas faculdades profundamente entorpecidas, contra as quais tiveram de fracassar, supondo que foram tentados e dirigidos para a educação delas, todos os esforços reunidos de uma metafísica recémnascida, ainda entravada pelo preconceito das ideias inatas, e de uma medicina cujas concepções, necessariamente limitadas por uma doutrina totalmente mecânica, não podiam elevar-se às considerações filosóficas das doenças do entendimento (Itard, 1801/ 2000, p. 126-127).

Até as sensações corporais de Victor pareciam totalmente diferentes daquelas experimentadas por 
aqueles que sempre viveram em sociedade. $U$ menino foi encontrado completamente nu. Durante anos enfrentara os frios mais rigorosos de inverno, sem qualquer agasalho que 0 protegesse da baixa temperatura. Esse fato também levantava suspeitas. Os inativistas perguntavam se, pelo fato de Victor ter sobrevivido a temperaturas ditas não suportadas por um humano, seria ele humano. Itard relata que Victor, na vida em comum com os outros homens, não tinha gosto pelos nossos prazeres, pelos nossos costumes, mas possuía uma vida solitária e com gosto pela liberdade dos campos. 0 médico refere-se à dificuldade do menino em acompanhá-lo em passos lentos e comedidos, pois andava de forma pesada quando calçado, porém com tendência contínua a retomar 0 galope ou o trote. Ele tinha também o hábito de cheirar tudo que lhe apresentavam, inclusive o que para nós é considerado inodoro. Sua mastigação era realizada pelos dentes incisivos, semelhante a alguns roedores. Em uma tarde em que se perdera na Rue de l'Enfer, foi encontrado apenas na caída da noite por sua governanta, mas foi só depois de ter-lhe farejado as mãos e os braços duas ou três vezes que ele se decidiu a segui-la e deixou explodir a alegria que sentia por tê-la reencontrado (Itard, 1806/ 2000, p. 195).

Itard vai, aos poucos, modificando as suas impressões iniciais acerca de Victor. A princípio acreditava que o menino era indiferente a tudo, inclusive ao olfato. Posteriormente passa a afirmar que possui, sim, uma relação olfativa, porém distinta da nossa. Em um primeiro momento, Itard afirma que 0 menino deveria ser treinado em seus atos de imitação, considerando que ele não possuía, sequer, a capacidade de imitar qualquer ato, nem mesmo entendia que devia imitá-los. Posteriormente, Itard presenciou a imitação dos atos mais grosseiros, como levantar os braços, abrir e fechar as mãos, até pegar o giz e imitar a escrita.

0 médico relata ainda ter enchido o nariz do menino de tabaco para provocar-lhe o espirro, porém, infeliz com 0 resultado, alega que o jovem não possuía entre 0 órgão do olfato, da respiração e da vista nenhuma dessas relações simpáticas que são consideradas partes constituintes da sensibilidade de nossos sentidos, e que deveriam ter provocado lágnimas ou espirros, nesse caso. Novamente Itard parece querer asseverar a insustentabilidade das teses inativistas, ao se perguntar se seria possível afirmar que 0 fato de não espirrar era resultado da falta de algum elemento biológico. 0 médico observou que até 0 espirro é aprendido, pois, conforme comenta, a primeira vez em que Victor espirrou ele tomou um susto e correu para a cama. Q uanto ao aprendizado das sensações corpóreas, Itard relata que as ensinou ao menino, dando-lhe banhos diários com temperaturas altıssımas, para que v ictor começasse a sentir o frio e 0 calor, e foi então que, com o tempo, ele passou a reclamar de frio nas águas mornas. Em uma tese inativista, considerar-se-ia que, por ser comum sentirmos calor e frio, essas sensações só precisariam ser despertadas, pois já estariam ali. Porém, Victor não a desenvolvera. Itard parecia acreditar que até as sensações precisavam ser aprendidas.

Após estabelecer algumas metas para 0 tratamento moral e educacional do menino, Itard iniciou seu desenvolvimento pelo órgão do ouvido. A princípio o menino tinha apenas de identificar os sons, porém era tão distraído que foi necessário vendá-lo para que pudesse se concentrar. É interessante observar como, por ser alguém indiferente a tudo, qualquer movimento de luz ou som o pudesse desconcentrar. Foi curioso observar que o jovem Victor começou a sentir prazer nas lições, como registra o Dr. Itard, sobretudo as lições em que ouvia 0 som da voz humana, quando vinha algumas vezes com a venda na mão pedindo-lhe para atá-la sobre a cabeça. Aos poucos o menino começou a distinguir diferentes entonações da linguagem, acompanhadas dos sentimentos de censura, cólera, amizade, dentre outros.

Após ensinar os sentidos a perceber e distinguir novos objetos, a atenção a deter-se neles, 0 juízo a compará-los e a memória a guardá-los, Itard tentava fazer com que Victor comunicasse as ideias. Eventualmente, quando não conseguia o resultado esperado, 0 médico reagia de forma impaciente e desencorajadora. Em uma ocasião, disse algumas palavras ao menino, levando-o a uma crise tremenda de choro. Itard (1806/ 2000) relata ter observado que após essas crises, que iam até as lágrimas, Victor desenvolvia, subitamente, uma inteligência que 0 deixava apto a superar, imediatamente depois, tal dificuldade. 0 professor percebeu, também, que, se após essas crises ele mudasse 0 tom das reprimendas por carinhos e encorajamento, obtinha do menino um acréscimo da emoção, que dobrava o efeito que dela esperava.

Itard, após ensinar 0 desenvolvimento das palavras, com algumas dificuldades, em especial em relação ao nomear as partes do corpo, começou a ensinar as qualidades sensíveis dos corpos, como as de cor, de peso, de resistência, etc. Posteriormente ensinou os adjetivos, verbos, a escrita e as faculdades afetivas. $\mathrm{O}$ menino não tinha muitas dificuldades em se expressar em alguns afetos, demonstrando sua impaciência e tédio diante de curiosos que apareciam, ao mandá-los embora apresentando-lhes suas respectivas bengalas, luvas e chapéu e empurrando-os suavemente para a porta. 
Ainda na educação de Victor, Itard tinha o hábito de fazer elogios quando o menino acertava os exercícios e, de maneira inversa, emitir seu descontentamento e por vezes aprisioná-lo no gabinete escuro. Certo dia, esperando elogios, Victor foi surpreendido por um injusto descontentamento por parte de Itard, que tentou a todo custo prendê-lo no gabinete como se ele houvesse falhado. O jovem, tomado de fúria, mordeu o professor, trazendo-lhe imensa satisfação. Itard declarou, com essa situação, ter elevado Victor à altura do homem moral. É curioso observar que o menino, posteriormente, adquiriu 0 prazer em arrumar as coisas, e muitas vezes se levantava da cama para arrumar algo em desordem em seu quarto. 0 gosto pela ordem foi algo que se acentuou em diversos exercícios. Por exemplo, para memorizar as letras do alfabeto Victor tinha muita dificuldade, mas conseguia realizá-lo quando mantinha a ordem na arrumação das letras, feitas de madeira, para o suposto exercício.

Dr. Itard pareceu surpreso com a indiferença do jovem Victor com relação às mulheres, esperando a cada dia 0 aparecimento desse sentimento universal. No entanto, essa puberdade explodiu, colocando-0 mais próximo do sexo feminino pelo convívio, mas sem preferências sexuais. Certa vez, numa reunião social, o menino se aproximava de uma garota, a beliscava e, posteriormente, a repelia com irritação, dirigindo-se a outra, com quem se comportava da mesma maneira. Um dia conseguiu ir mais longe; após as tais carícias ele a puxou, sem violência, a uma alcova. Ali, embaraçado, com uma mescla de alegria e tristeza, solicitou as carícias, de sua dama apresentando-lhe as bochechas. Todas suas demonstrações amorosas acabaram com um movimento de irritação, que o fazia repelir o objeto de suas inclinações. 0 jovem parou de procurar em carícias alívio para seus desejos, e, apesar dos dias atarefados e dos muitos exercícios, Victor passava de uma atitude doce para uma tristeza, ansiedade e furor que 0 levavam a suspiros, lágrimas, gritos, à prática de rasgar suas roupas, ao sangramento pelos ouvidos e nariz e, por vezes, a mordidas e arranhões em sua governanta. Dr. Itard conclui que os primeiros fenômenos da puberdade, assim como a preferência sexual, lançam muitas dúvidas sobre certas afeições do coração, que olhamos como naturais.

Victor, a partir dos 18 anos, fica sob a tutela de sua governanta e vem a falecer por volta dos 40 anos. É uma pena não termos mais acesso às posteriores informações de sua vida. Ele não aprende a falar e pouquíssimo a escrever, no entanto, aprende, como afirma Itard, muitas das faculdades sensitivas, afetivas e morais.
Quando nos vemos ao lado de um jovem cuja vivência foi tão distinta da nossa, tomados por uma curiosidade tremenda e uma aversão ao mistério, buscamos, antes de tudo, fazê-lo ser como somos, sentir como sentimos, e julgamo-lo um idiota, em vez de enxergá-lo tal qual era, alguém que, sem maiores dificuldades e idiotias, cuidava muito bem de si em um ambiente, para nós, extremamente selvagem.

\section{O saraí na primira tapa de vida: indkteminação, intenionalidadeehistoricidade}

Em Ser eterpo Heidegger (1927/ 1988) já afirma que as estruturas existenciais não são estruturas ônticas e, nesse sentido, podem ser encontradas em qualquer experiência de mundo do ser-aí. Isso não diz respeito apenas à caracterização do ser-aí europeu desenvolvido, mas tanto no que se refere ao ser-aí infantil como ao que se refere ao ser-aí dos povos primitivos, o que estará em questão é o ser-aí humano, sendo a base do ser-aí humano 0 seu caráter essencialmente histórico. Por mais que Heidegger (1928/2008) afirme que as estruturas existenciais se mostram mais claramente no homem primitivo ou no aborígine, em virtude da simplicidade da vida desses homens, as estruturas históricas existenciais estão presentes em seu caráter de aí em todos os homens, em todas as épocas, lugares ou fase de desenvolvimento de suas vidas, e é a partir desse caráter que o ser-aí conquista o poder-ser que ele é.

Pensar no ser-aí das crianças requer, primeiramente, que se esclareça de que modo se dá esse ente em seu primeiro momento de vida. Para tanto, seguiremos assumindo uma atitude fenomenológica, para assim podermos deixar que 0 sentido do fenômeno se dê no seu próprio campo de mostração. Husserl (1952) denomina esse posicionamento, referente àquilo que se mostra, de atitude antinatural, a qual consiste em reduções fenomenológicas, exercício incessante para alcançar 0 fenômeno, deixando para trás todas as pressuposições sobre o mesmo. Ainda em Husserl vamos considerar a sua tese de que a consciência não pode ser tomada a partir da concepção de que ela se constitui como substância e se encontra espacial e temporalmente determinada. Husserl confere à consciência uma imanência, ou seja, o caráter de intencionalidade, de estar sempre dirigida a... Proceder a uma investigação fenomenológica da experiência infantil consiste em ir ao fenômeno da intencionalidade em sua imanência, tal como esta se dá nessa etapa da vida humana. Partimos da concepção de que o som expressado pelo recémnascido, no ato de nascer, já é ato intencional, pois todo e qualquer ato é intencional e ocorre na cooriginalidade homem-mundo. D essa forma, o ato de 
nascer já implica essa co-originalidade, e é nesta cooriginalidade e apenas assim que a criança emite 0 som. É necessária a copresença, sem a qual o som não se dá. A intencionalidade constitutiva do existir (a cooriginalidade homem-mundo, ser-aí) se dá em todos os atos: dormir, acordar, alimentar-se, irritar-se, etc.

Iniciemos, portanto, com algumas considerações acerca da criança e dos momentos iniciais de sua vida, com base em posicionamentos teóricos comumente conhecidos. Em uma postura natural, seja da ciência ou do senso comum, a vida é tomada como uma linha em que, pensada onticamente, a morte é uma espécie de término e o nascimento, o início. Assim, uma teoria do nascimento (Heidegger, 1928/2008) pressupõe algo que nasce para depois existir, de acordo com aquilo que foi biologicamente determinado. Estas teorias postulam que primeiramente nasce um corpo biológico e depois vem 0 psiquismo. As teorias do desenvolvimento, como, por exemplo, a de Piaget (1964/ 1972), pressupõem que o bebê ao nascer, em seu estado de sonolência, constitui-se em um eu autocentrado, encapsulado, totalmente isolado do mundo. Esse estado de sonolência em que o recémnascido se encontra é descrito pela teoria de Piaget como egocentrismo, visto que esse ser estaria encerrado em si mesmo. A criança é, assim, interpretada inicialmente como uma espécie de eu embrionário, completamente fechado em si e que paulatinamente vai se abrindo para o mundo. Como então, no universo da psicologia, podemos pensar a criança abandonando toda e qualquer teoria do desenvolvimento? Vamos acompanhar Heidegger em suas considerações e tentar viabilizar interpretações outras da vida infantil.

Em Ser etempo(1927/ 1988), Heidegger já refuta a posição das teorias do desenvolvimento, que pressupõem, logo de início, uma representação sobre o nascimento e a morte. Em um posicionamento acerca da criança, pautado no pensamento de Heidegger, não faria nenhum sentido falar de uma teoria do nascimento em um ente dotado de caráter de poderser. Heidegger defende que o nascimento é tardio, já que não há nada antes da existência, por isso não se preocupa com o nascimento, uma vez que este não se encontra no início: "vale dizer que aquilo que primeiramente nos parece ser o que fomos primeiro é, em meio ao conhecimento, o mais tardio" (Heidegger, 1928/ 2008, p. 131). Para Heidegger, primeiramente é preciso ser no mundo para depois, então, se pensar no caráter biológico. Assim ele, com a noção de ser-aí como jogado, acrescenta que o nascimento é abrupto. Ao nascer o ser-aí já é dotado de intencionalidade, logo, sempre direcionado para, e, desse modo, acaba prescindindo de qualquer teoria sobre 0 nascimento.
Quanto às considerações acerca da vida como se constituindo em uma linha, cuja morte é seu término, ressaltamos que retroceder ao nascimento não é inverter 0 ser-para-a-morte. Nem Heidegger considera o nascimento o outro polo extremo do ser-aí, portanto, não se insere aí a mesma problemática da morte. A experiência originária do ser-aí com a finitude diz respeito ao horizonte de realização do ser-aí.

Heidegger (1928/ 2008) chama a atenção para 0 modo de mostração do ser-aí de uma criança no seu primeiro momento de ser-aí terreno, em sua intencionalidade. Ele se refere ao choro e à agitação como dirigidos para..., evidenciando que tanto o choro quanto a agitação se dão no mundo. Logo que a criança nasce nos deparamos com o choro, com o movimento agitado no mundo, no espaço, sem qualquer finalidade e, contudo dirigido para.... Para entendermos esse espaço no qual a existência acontece, cabe ressaltar a diferença entre finalidade e orientação. No ato de chorar e agitar-se da criança há uma ausência de finalidade, o que não significa desorientação. 0 ato encontra-se orientado, mas isso não significa dizer que está voltado a uma finalidade. "Ao contrário, orientação significa em geral estar-direcionado a..., estar-direcionado-para..., estar direcionado para fora de..." (Heidegger, 1928/2008, p. 131). Essa interpretação já diz respeito à intencionalidade, que nessa perspectiva é o lugar onde se articula o ser-aí.

Heidegger chama a atenção para o equívoco de se pensar 0 modo de ser do recém-nascido como isolamento, pela sua quietude e seu estado de sono e de sonolência. Esse modo de estar no mundo do bebê não significa, de modo algum, isolamento em seu caráter de positividade. A aversão, a defesa e essa necessidade autocentrada de quietude, calor e sono têm um caráter negativo totalmente peculiar. 0 estado de sonolência no qual se encontra tal ser-aí primevo não significa que ainda não exista uma relação. Ao contrário, isso apenas indica que esse comportar-se em relação-a ainda não tem uma finalidade determinada. Basta um leve ruído para que 0 ato de estremecer da criança apareça, denotando o caráter intencional de seu ato. Para Heidegger (1928/2008), a "reação" da criança tem efetivamente 0 caráter de choque, bem como 0 primeiro choro, por ser um choque bem determinado. 0 ato de assustar-se da criança evidencia que esta já está articulada com o espaço, por isso qualquer coisa que aconteça nesse espaço a desperta. Todo esse primeiro momento regula-se por choque e susto, o que denota que a ação encontra-se para fora intencionalidade. Se assim não fosse, e ela se encontrasse fechada em si mesma, não reaginia ao mundo externo tão imediatamente. A intencionalidade diz da exposição, ou seja, tudo que acontece projeta 0 
ser-aí imediatamente para além do acontecimento. 0 ato de assustar-se é uma sensibilidade à perturbação, uma forma originária do deter-se em reparar em algo, um comportamento inerente ao deixar algo ser. A perplexidade, o susto e o choque já são, contudo, uma disposição de ânimo. A essência do choque só pode ser esclarecida em conexão com o fenômeno do susto e do medo. 0 choque significa que o encontrar-se em uma disposição de ânimo é perturbado, que entra em cena um desconforto, que deverá ser repelido. Logo, a criança é intencionalidade, e como tal se dá sempre em um espaço de articulação eu/ mundo.

Nesse espaço de articulação, encontramos a estrutura intencional dos fenômenos - repulsa, rejeição, defesa -, para podermos então interpretar 0 estado da criança em sua originalidade. Os fenômenos da intencionalidade já se revelam na primeira situação, na qual se encontra um ser-aí em sua entrega ao mundo, inicialmente desvalida e indeterminada. A repulsa, rejeição e defesa precisam ser diferenciadas para que possamos entender a ação do ser-aí infantil em seu campo de aparição. Segundo Heidegger (1928/ 2008), a repulsa é um mero esquivar-se de... No esquivar-se já está presente certa rejeição, uma recusa a... Ao nos esquivarmos de algo denunciamos uma contraposição, ainda que não ativa. $\mathrm{Na}$ defesa se inicia 0 contramovimento propriamente dito, o contrapor-se. Portanto repulsa, rejeição, defesa, tudo isso é um sinal de que o recém-nascido não se encontra ensimesmado. Essas reações apontam para o caráter de abertura em que o ser-aí sempre se encontra, sempre relacionado ao mundo.

\section{Considerações finais e conclusão}

Defendemos, então, o caráter de indeterminação da existência, que permitiu ao menino Victor encontrar-se e constituir-se em meio àquilo que se mostrava como possibilidade. E é nessa indeterminação que se encontra a sua liberdade. Nossa posição é de que é o mundo que torna possível, mas não é ele que determina um modo de ser criança. É na presença da familiaridade que 0 sentido se constitui. 0 menino Victor andava curvado e galopando, comia como um roedor e brincava na chuva, pois era desse modo que 0 mundo de possibilidades se lhe apresentava. Caso a determinação humana fosse pelo carácter biológico, independentemente do meio em que ele se encontrasse, Victor andaria, comeria, enfim, se comportaria como os homens se comportam. Por outro lado, se os comportamentos fossem aprendidos, o menino aprenderia a agir tal como os animais a sua volta, sem nenhuma variação que sua constituição intencional pudesse proporcionar. Por exemplo, ele não andaria curvado, mas apenas nas quatro patas. Se sua natureza ingênua e boa determinasse a sua humanidade, que apenas o social corromperia, Victor jamais se expressaria com os gritos, repulsa e até com atos agressivos dirigidos à governanta e nas relações com aqueles que cuidavam dele. Esse menino, em seu ter de ser e poder ser, em qualquer meio em que se encontrasse, teria de se comportar, em termos heideggerianos, teria de ser (Heidegger, 1927/ 1988). E uma vez tendo de ser em um mundo de possibilidades, sempre já se abriu como um poder ser.

Assim, uma criança criada em meio aos animais, dado o seu caráter de ser-aí, vai seguir a familiaridade que se apresenta, nesse caso, o modo animal de se comportar diante do que lhe vem ao encontro: ela vai andar meio erguida, vai alimentar-se daquilo que se mostra como alimento, vai sentir menos frio, vai caçar, mas nunca vai se tornar lobo ou qualquer outro animal presente em seu espaço existencial. Esses animais apresentam-se em uma abertura, porém com determinações dadas pela sua natureza biológica. As características do comportamento dos animais não se articulam pela negatividade, ou seja, pelo poder-ser, pois o animal já tem mais determinações de natureza biológica, a princípio. Já uma criança, entre os animais, não vai agir desde o principio como homem, isto porque ela carece, para agir como homem, de mundo compartilhado com os homens. Mas, pelo seu caráter de negatividade, seus significados vão se constituir na presença da familiaridade, que no caso do menino Victor aconteceu, de início, em meio ao mundo selvagem (animal).

Victor, quando se encontra em meio aos homens, começa então a atentar-se aos odores, à percepção dos objetos, às sensibilidades táteis do mundo em que então se encontrava. Nisso deparamo-nos com 0 caráter intencional da constituição da existência. Se considerássemos apenas a audição, o olfato, o tátil e a gustação como sensibilidades oriundas do corpo biológico, ou ainda se todas essas coisas fossem apenas aprendidas, elas se manteriam como uma unidade invariável ou ocorreria apenas um maior repertório de respostas. Consideramos que em Victor 0 ato de ouvir, de perceber e de sentir acontece no espaço intencional em que essas determinações, afinal, podem se dar.

Em síntese, a história de Victor aponta para a intencionalidade de base ser-aí mundo como o espaço em que a existência se dá. Daí afirmarmos a impossibilidade de se pensar a existência de Victor além dessa intencionalidade. A tarefa da ontologia fundamental, tal como proposta por Heidegger, consiste em buscar o sentido do ser partindo do ser-aí como o lugar no qual acontece historicamente tal sentido. Esse lugar se baseia, por sua vez, no aí, no 
mundo e na inseparabilidade homem-mundo; portanto, não poderíamos pensar Victor por meio de qualquer determinação que se associe essencialmente a ele, justamente porque a sua única determinação consiste no caráter do poder-ser, sempre atravessado pelo horizonte histórico em que ele se encontra.

\section{Referências}

Feijoo, A. M. (2011). A existênaia alémdb sujęta Rio de Janeiro: Via Verita IFEN.

Guinsburg, J. (2008). O romantismo São Paulo: Perspectiva.

Heidegger, M. (1988). Ser etempa (M. M. S. Cavalcante, trad.). Petropólis: Vozes. (O riginal publicado em 1927).

Heidegger. M. (2008). Introução à filosafia (M. A. Casanova, trad.). São Paulo: Martins Fontes. (O riginal publicado em 1928).

Husserl, E. (1952). A filoscia como dênia nigarosa (v. 1). Coimbra: Revista Logos. (Original publicado em 1910).

Husserl, E. (2007). Inestigaç̃es lógicas (P. M. S. Alves \& C. A. Morujão, trad.). Lisboa: Centro de Filosofia da Universidade de Lisboa. (O riginal publicado em 1900).
Itard, J. (2000). Da educação de um homem selvagem ou dos primeiros desenvolvimentos físicos e morais do jovem Selvagem do Aveyron. Em L. Banks-Leite \& I. Galvão (O rgs.), A educação deum setvagem as experiênaias peelagógicas de Jenn Itard (pp. 117-177, M. E. Galvão, trad.). São Paulo: Cortez. (O riginal publicado em 1801).

Itard, J. (2000). Relatório feito a sua excelência o Ministro do Interior sobre os novos desenvolvimentos e o estado atual do Selvagem do Aveyron. Em L. Banks-Leite \& I. Galvão (O rgs.), A eduração deumsitvagem as experiênias peclagógicas de Jæn Itard (pp. 178-229, M. E. Galvão, trad.). São Paulo: Cortez. (O riginal publicado em 1806).

Piaget, J. (1972). Seis estudos de psicoga (M. A. Magalhães, trad.). Rio de Janeiro: Forense. (O riginal publicado em 1964).

Sawrey, J., \& Telford, C. (1967). Psicdoga educadional. (I. W. Bonow, trad.). Rio de Janeiro: Ao Livro Técnico. (O riginal publicado em 1958).

Watson, J. B. (1930). Behavioism Nova Iorque: W. W. Norton.

Reedidoem27/ 07/ 2011

Reformuladbem10/ 05/ 2012 Aprovadoem11/ 06/ 2012

Sobre as autoras:

Ana Maria Lopez Calvo de Feijoo é pós-doutora em filosofia pela Universidade Federal do Rio de Janeiro, doutora em Psicologia pela Universidade Federal do Rio de Janeiro, professora adjunta do Instituto de Psicologia e do Programa de Pós-G raduação em Psicologia Social da Universidade do Estado do Rio de Janeiro, professora, supervisora e coordenadora de Pesquisa no Instituto de Psicologia Fenomenológico-Existencial do Rio de Janeiro (IFEN). É membro da Diretoria da Associação Latinoamericana de Psicoterapia Existencial (ALPE) e psicóloga clínica, com ênfase em Intervenção Terapêutica.

Débora Gill é mestranda em filosofia pela Pontifícia Universidade Católica do Rio de Janeiro, pós-graduada em Psicologia Clínica pelo Instituto de Psicologia Fenomenológico-Existencial do Rio de Janeiro - IFEN, pesquisadora pelo Diretório dos Grupos de Pesquisa do Brasil, CNPQ, Brasil e psicóloga clínica na perspectiva fenomenológicoexistencial.

Myriam Moreira Protasio é doutoranda em filosofia pela Universidade do Estado do Rio de Janeiro, mestre em filosofia pela Universidade do Estado do Rio de Janeiro, especialista em Psicologia Clínica pelo Instituto de Psicologia Fenomenológico-Existencial do Rio de Janeiro - IFEN, professora, supervisora e coordenadora de Pesquisa no IFEN. É membro da Diretoria da Associação Latinoamericana de Psicoterapia Existencial (ALPE), pesquisadora pelo Diretório dos Grupos de Pesquisa do Brasil, CNPQ, Brasil, e psicóloga clínica na perspectiva fenomenológico-existencial.

Contato com as autoras:

Rua Barão de Piracinunga, 62 -Tijuca - CEP - 20520-170. Rio de Janeiro.

E-mail: feijoo@ifen.com.br 